\title{
Comprehensive Analysis of Severe Viral Infections of Respiratory Tract admitted to PICUs during the Winter Season in Turkey
}

\author{
Esra Kockuzu ${ }^{1}$, Benan Bayrakcı ${ }^{2}$, Selman Kesici ${ }^{3}$, Agop Cıtak $^{4}$, Bulent Karapınar ${ }^{5}$, Serhat Emeksiz ${ }^{6}$, Ayşe Berna Anıl ${ }^{7}$ \\ Tanıl Kendirli ${ }^{8}$, Ufuk Yukselmis ${ }^{9}$, Esra Sevketoglu ${ }^{10}$, Şukru Paksu ${ }^{11}$, Onur Kutlu ${ }^{12}$, Hasan Agın ${ }^{13}$, Dincer Yıldızdas ${ }^{14}$, \\ Halil Keskin ${ }^{15}$, Gokhan Kalkan ${ }^{16}$, Arzu Hasanoglu ${ }^{17}$, Mutlu Uysal Yazıcl ${ }^{18}$, Guntulu Sık ${ }^{19}$, Arda Kılınc ${ }^{20}$, Fatih Durak ${ }^{21}$, \\ Oktay Perk $^{22}$, Mey Talip ${ }^{23}$, Nazik Yener ${ }^{24}$, Selcuk Uzuner ${ }^{25}$
}

\begin{abstract}
Objectives: To analyze the course of seasonal viral infections of respiratory tract in patients hospitalized in pediatric intensive care units (PICU) of 16 centers in Turkey.

Materials and methods: It is a retrospective, observational, and multicenter study conducted in 16 tertiary PICUs in Turkey includes a total of 302 children with viral cause in the nasal swab which required PICU admission with no interventions.

Results: Median age of patients was 12 months. Respiratory syncytial virus (RSV) was more common in patients over one year of age whereas influenza, human Bocavirus in patients above a year of age was more common $(p<0.05)$. Clinical presentations influencing mortality were neurologic symptoms, tachycardia, hypoxia, hypotension, elevated lactate, and acidosis. The critical pH value related with mortality was $\leq 7.10$, and critical $\mathrm{PCO}_{2} \geq 60 \mathrm{~mm} \mathrm{Hg}$.

Conclusion: Our findings demonstrate that patients with neurological symptoms, tachycardia, hypoxia, hypotension, acidosis, impaired liver, and renal function at the time of admission exhibit more severe mortal progressions. Presence of acidosis and multiorgan failure was found to be predictor for mortality. Knowledge of clinical presentation and age-related variations among seasonal viruses may give a clue about severe course and prognosis. By presenting the analyzed data of $302 \mathrm{PICU}$ admissions, current study reveals severity of viral respiratory tract infections and release tips for handling them.

Keywords: Mortality, Multi organ failure, Pediatric intensive care unit, Seasonal, Viruses

Indian Journal of Critical Care Medicine (2019): 10.5005/jp-journals-10071-23177
\end{abstract}

\section{INTRODUCTION}

Microbial agents that most commonly lead to childhood infections are viruses. In developed countries, infants and preschool children have viral infection 6-10 times in a year, and school-age children and adolescents have 3-5 times in a year. ${ }^{1}$ In a study published by American Centers for Disease Control and Prevention in 2015, pathogens were detected in $80 \%$ of 2,254 pneumonia cases in patients aged between a day and 17 years, $66 \%$ of these pathogens were viruses. $^{2,3}$

Viruses may cause several clinical conditions that require hospitalization in a PICU such as bronchiolitis, pneumonia, chronic lung diseases, and more severe manifestations such as myocarditis, encephalitis, and sepsis. Besides the known agents, recently new generation viruses including human metapneumovirus (HMPV), coronavirus, and bocavirus have also been lead to cause these manifestations. ${ }^{4,5}$

In this study, it is aimed to bring out the clinical characteristics of patients who had viral infections requiring PICU admission during winter season in Turkey.

\section{Materials and Methods}

PICUs of 16 centers spread to Turkey participated in this retrospective observational study. Children between one month and 18 years of age with a viral cause in the nasal swab, who required PICU

\begin{abstract}
${ }^{1,2,18}$ Department of Pediatric Intensive Care Unit, Hacettepe University Faculty of Medicine, Ankara, Turkey

${ }^{3,19}$ Clinic of Pediatric Intensive Care Unit, Dr. Sami Ulus Child Health and Disease Training and Research Hospital, Ankara, Turkey

${ }^{4}$ Department of Pediatric Intensive Care Unit, Acıbadem University Faculty of Medicine, Istanbul, Turkey

5,20,21 Department of Pediatric Intensive Care Unit, Ege University Faculty of Medicine, Izmir, Turkey

${ }^{6}$ Clinic of Pediatric Intensive Care Unit, Ankara Pediatric Hematology Oncology Training and Research Hospital, Ankara, Turkey

${ }^{7}$ Clinic of Pediatric Intensive Care Unit, Ankara Tepecik Training and Research Hospital, Izmir, Turkey

${ }^{8,22}$ Department of Pediatric Intensive Care Unit, Ankara University Faculty of Medicine, Ankara, Turkey

${ }^{9}$ Clinic of Pediatric Intensive Care Unit, Kartal Lutfi Kırdar Education Research Hospital, Istanbul, Turkey

${ }^{10,23}$ Clinic of Pediatric Intensive Care Unit, Bakırkoy Sadi Konuk Education Research Hospital, Istanbul, Turkey

${ }^{11,24}$ Department of Pediatric Intensive Care Unit, Ondokuz Mayıs University, Faculty of Medicine, Samsun, Turkey 12,25Department of Pediatric Intensive Care Unit, Bezmialem University Faculty of Medicine, Istanbul, Turkey

${ }^{13}$ Clinic of Pediatric Intensive Care Unit Dr. Behcet Uz Education Research Hospital, Izmir, Turkey
\end{abstract}

Contd...

() The Author(s). 2019 Open Access This article is distributed under the terms of the Creative Commons Attribution 4.0 International License (https://creativecommons. org/licenses/by-nc/4.0/), which permits unrestricted use, distribution, and non-commercial reproduction in any medium, provided you give appropriate credit to the original author(s) and the source, provide a link to the Creative Commons license, and indicate if changes were made. The Creative Commons Public Domain Dedication waiver (http://creativecommons.org/publicdomain/zero/1.0/) applies to the data made available in this article, unless otherwise stated. 
Contd...

${ }^{14}$ Department of Pediatric Intensive Care Unit, Cukurova University Faculty of Medicine, Adana, Turkey

${ }^{15}$ Department of Pediatric Intensive Care Unit, Ataturk University Faculty of Medicine, Erzurum, Turkey

${ }^{16}$ Department of Pediatric Intensive Care Unit, Gazi University Faculty of Medicine, Ankara, Turkey

${ }^{17}$ Department of Pediatric Intensive Care Unit, Gaziantep University Faculty of Medicine, Gaziantep, Turkey

Corresponding Author: Benan Bayrakcl, Department of Pediatric Intensive Care Unit, Hacettepe University Faculty of Medicine, Ankara, Turkey, e-mail: bbenan@yahoo.com, Phone: +90 5337493399

How to cite this article: Kockuzu E, Bayrakcı B, Kesici S, Citak A, Karapınar K, Emeksiz S, et al. Comprehensive Analysis of Severe Viral Infections of Respiratory Tract admitted to PICUs During the Winter Season in Turkey. Indian J Crit Care Med 2019;23(6):263-269.

Source of support: Nil

Conflict of interest: None

admission in the winter 2016-2017 (October-February) period, were included in the study. Approval for this study was obtained from the Hacettepe University Research Ethics Committee. Data form was filled for each patient who had a positive viral polymerase chain reaction in nasal swab sample. The form included demographic data, presentation symptoms, physical examination findings, laboratory findings, isolated virus, indication and diagnosis of PICU admission, radiological findings, underlying disease, organ failure, treatment, accompanying bacterial infection, pediatric mortality scores [Pediatric Risk of Mortality (PRISM), Pediatric Logistic Organ Dysfunction (PELOD)], length of hospital, and PICU stay. Anemia, thrombocytopenia-thrombocytosis, and leukocytosis-leukopenia were recorded according to age group. Oxygen saturation $\left(\mathrm{SO}_{2}\right)$ below $92 \%$ is defined as hypoxia. Treatment options were defined as respiratory support treatments, antimicrobial treatments, renal replacement treatments, plasma exchange, and extracorporeal membrane oxygenation (ECMO). Indication for PICU admission was classified as respiratory failure, cardiovascular dysfunction, neurological dysfunction, and multiple organ dysfunction syndrome (MODS). Organ failures were evaluated according to Goldstein 2005 MODS criteria. ${ }^{6}$

Median age of the patients in the study was 12 months. Patients were separated into two groups according to median age. Two groups (0-12 months, 13 months, and over) were compared in terms of presenting findings (clinical, laboratory, and radiological), indication of PICU admission, isolated viruses, organ failures, treatment options, underlying disease, and PICU mortality scores.

Presenting findings, indication of PICU admission, isolated viruses, organ failures, treatment options, underlying diseases, PICU mortality scores, and presence of single or multiple viruses were analyzed through four parameters (duration of MV, PICU, hospital, and mortality).

\section{Statistical Analysis}

Initially descriptive properties of variables (mean, median, number, and percentage) were found. Numerical variables were checked for normal distribution. Student t test was used for normally distributed numerical variables. Mann-Whitney $U$ test was used for variables with no normal distribution when two groups were compared. In comparison with the numerical values of multiple groups, ANOVA was used for variables with normal distribution and Kruskal Vallis test was used for variables with no normal distribution. Comparison of categorical variables was carried out by chi-square test and Fisher Exact test. The most effective presenting finding on mortality was revealed with regression analysis. Multivariate regression analysis was performed for determining mortality risk factor. Critical $\mathrm{pH}$ and $\mathrm{pCO}_{2}$ value were found with the ROC curve. ROC analysis was performed to evaluate the relationship between blood $\mathrm{pH}$ and mortality. The $p$-value $<0.05$ was considered as significant. The results were evaluated using the Statistical Package for Social Sciences - SPSS 17 (Chicago, USA) program.

\section{RESULTS}

Data of 302 patients with severe viral infections were followed in PICU of 16 centers in Turkey. Out of 302 patients, 113 (37\%) were girls and 189 (63\%) were boys. Mortality rate was $7.6 \%$ (23/302). The mean PRISM score was $37.2 \pm 13.2$ in patients who died and $11.1 \pm 10.3$ in patients discharged $(p<0.001)$. Median age of patients was 12 (4-36) months. Forty-seven percent of patients were under one year of age and $53 \%$ of patients were over one year of age. Mortality rate was $9.2 \%$ and $6.3 \%$ in each age groups, respectively ( $p=0.34)$. It was seen that $45.7 \%$ of the patients were admitted to the emergency department, $24.2 \%$ were admitted to the inpatient service of the same hospital, and $23.3 \%$ of the patients were accepted from the inpatient or emergency services of other hospitals. The mean duration of symptoms before admission to the hospital was $3.9 \pm 2.8$ days. Duration of stay in PICU was between one day and 116 days, hospital duration was between two days and 120 days.

Symptoms were cough in $78.1 \%$, fever in $62.5 \%$, nasal discharge in $45.6 \%$, gastrointestinal symptoms in $20.8 \%$, neurological symptoms (seizures, changes in consciousness) in $17.5 \%$, and rash in $4.6 \%$ of all patients. Hypoxia was found in $49 \%$, tachypnea in $43 \%$, fever in $40 \%$, tachycardia in $34 \%$, and hypotension in $7 \%$ of patients. Physical examinations revealed respiratory findings in $86 \%$, prolonged capillary filling in $32 \%$, neurological findings in $14 \%$, and gastrointestinal system findings in $10 \%$ of all patients.

Indication of PICU admission was respiratory dysfunction in $71.5 \%$, circulatory dysfunction in $10.2 \%$, neurologic dysfunction in $7.6 \%$, and MODS in $10.5 \%$ of patients. At the time of admission and in follow-up, respiratory failure was observed in $91.3 \%$, cardiovascular failure in $22.1 \%$, hematological failure in $15.2 \%$, renal failure in $10.2 \%$, and hepatic failure in $9.9 \%$ of patients. In regression analysis, MODS was found as a predictor for mortality [odds ratio: $20.5(95 \%)$ confidence interval (Cl): 5.8-72.1; $p=0.00]$

Anemia was found in $45.4 \%$, leukocytosis in $17.8 \%$, leukopenia in $14.2 \%$, thrombocytosis in $19.8 \%$, thrombocytopenia in $14.9 \%$, prolonged INR in $26.6 \%$, and electrolyte imbalance in $74.8 \%$ of patients. Acidosis was found in 55.2\%, alkalosis in 5.9\%, high $\mathrm{PCO}_{2}$ in $37.7 \%$, and elevated lactate in $56.9 \%$ of patients. The mean lactate value was $6.3 \pm 6.1$ in patients who died and $2.7 \pm 2.5$ in patients who were discharged $(p<0.001)$. In regression analysis, acidosis was found to be a predictor for mortality (odds ratio $2.5(95 \%) \mathrm{Cl}$, $1.2-4.8 ; p=0.007$ ). It was found that $\mathrm{pH} \leq 7.10$ negatively affected survival (specificity $97.9 \%$ and sensitivity $26.3 \%$ ). $\mathrm{PCO}_{2} \geq 60 \mathrm{~mm} \mathrm{Hg}$ was also shown to have negative effect on survival (specificity $78.1 \%$ and sensitivity $68.4 \%)$. Clinical and laboratory findings at the time of admission of patients associated with mortality are shown in Table 1 and age-related discriminating factors are shown in Table 2.

Anterior-posterior chest radiograph revealed positive findings in $86 \%$ of patients (infiltration in $74 \%$, atelectasis in $9 \%$, pleural effusion in $5 \%$, and pneumothorax in $4 \%$ ). No statistically 
Table 1: Presenting findings associated with mortality

\begin{tabular}{llll}
\hline & Discharged & Died & \\
Presenting Findings & $\%(n)$ & $\%(n)$ & $p^{*}$ \\
Tachycardia & $33(92)$ & $56.5(13)$ & 0.023 \\
Hypotension & $6.1(17)$ & $30.4(7)$ & 0.001 \\
Cutis marmaratus & $6.5(18)$ & $39.1(9)$ & $<0.001$ \\
Neurologic symptoms & $15.8(44)$ & $39.1(9)$ & 0.009 \\
Low albumin level & $26.2(73)$ & $65.2(15)$ & $<0.001$ \\
Prolonged INR & $23.7(66)$ & $52.2(12)$ & 0.003 \\
Hypocalcemia & $22.7(63)$ & $69.6(16)$ & 0.001 \\
Hypophosphatemia & $14(39)$ & $34.8(8)$ & $<0.005$ \\
Hypomagnesemia & $23.7(52)$ & $47.8(9)$ & $<0.005$ \\
Elevated ALT & $15.1(42)$ & $52.2(12)$ & $<0.001$ \\
Elevated AST & $25.7(71)$ & $60.9(14)$ & $<0.001$ \\
Elevated total bilirubin & $12.5(35)$ & $39.1(9)$ & 0.001 \\
Elevated direct bilirubin & $16.2(45)$ & $39.1(9)$ & 0.001 \\
Acidosis & $52.7(147)$ & $87(20)$ & 0.006 \\
\hline
\end{tabular}

*Number of patients(n); ${ }^{*} p$ is significant when it is $<0.05$

Table 2: Age related discriminating factors

\begin{tabular}{|c|c|c|c|}
\hline Presenting Symptoms & $\begin{array}{l}<12 \text { months } \\
\%(n)\end{array}$ & $\begin{array}{l}>12 \text { months } \\
\%(n)\end{array}$ & $p^{*}$ \\
\hline Respiratory symptoms & $79.6(113)$ & $91.9(147)$ & 0.002 \\
\hline Hypoxia & $43(61)$ & $55.3(88)$ & 0.032 \\
\hline Fever & $72.5(103)$ & $53.8(86)$ & 0.001 \\
\hline Tachycardia & $47.2(67)$ & $23.8(38)$ & $<0.001$ \\
\hline Neurologic symptoms & $22.5(32)$ & $13.1(21)$ & 0.032 \\
\hline Anemia & $52.1(74)$ & $39.4(63)$ & 0.026 \\
\hline Leukocytosis & $27.9(39)$ & $9.4(15)$ & $<0.001$ \\
\hline Thrombocytopenia & $24.6(35)$ & $6.3(10)$ & $<0.001$ \\
\hline Hyponatremia & $46.5(63)$ & $31.3(45)$ & $<0.013$ \\
\hline Hypocalcemia & $36.9(52)$ & $17.5(27)$ & $<0.001$ \\
\hline Hypomagnesemia & $33.1(47)$ & $18.8(30)$ & 0.015 \\
\hline High BUN level & 49.3(70) & $20.6(33)$ & $<0.001$ \\
\hline High creatine level & $21.8(31)$ & $13.1(21)$ & 0.045 \\
\hline Hypoalbuminemia & $38.7(55)$ & $20.6(33)$ & 0.001 \\
\hline \multicolumn{4}{|l|}{ Indication of Picu Admission } \\
\hline Pulmonary dysfunction & $59.2(84)$ & $82.5(132)$ & $<0.001$ \\
\hline Neurological dysfunction & 13.4(19) & $2.5(4)$ & $<0.001$ \\
\hline Circulatory dysfunction & $14.1(20)$ & $6.9(11)$ & $<0.039$ \\
\hline \multicolumn{4}{|c|}{ Organ Failure during Hospitalization and Follow-Up } \\
\hline Neurologic failure & $21.8(31)$ & $8.8(14)$ & 0.005 \\
\hline Hematologic failure & $21.9(30)$ & $10.1(16)$ & 0.005 \\
\hline \multicolumn{4}{|l|}{ Isolated Virus } \\
\hline RSV & $23.2(33)$ & $55(88)$ & $<0.001$ \\
\hline Influenza & 27.5(39) & $13.8(22)$ & 0.003 \\
\hline Human bocavirus & $12.7(18)$ & $3.8(6)$ & 0.004 \\
\hline \multicolumn{4}{|l|}{ Others } \\
\hline Need for mechanical ventilator & $37.5(60)$ & $54.2(77)$ & 0.004 \\
\hline Hospitalization duration * & 12 (9-23) days & 17 (9-28) days & 0.04 \\
\hline Underlying disease & $65.5(93)$ & $34.5(68)$ & $<0.001$ \\
\hline
\end{tabular}


Table 3: Relationship of virus type with mortality

\begin{tabular}{llllll}
\hline & $(A)$ & $(B)$ & $(C)$ & $(D)$ & $(E)$ \\
Viruses & $\%(n)$ & $\%(n)$ & $\%(n)$ & $\%(n)$ & $(D / C) \%$ \\
\hline RSV & $40(121)$ & $17.4(4)$ & $40.6(106)$ & $21.1(4)$ & 3.7 \\
Influenza & $20.1(61)$ & $17.4(4)$ & $17.2(45)$ & $21.1(4)$ & 8.8 \\
Rhinovirus & $19.2(58)$ & $17.4(4)$ & $14.9(39)$ & $5.3(1)$ & 2.5 \\
Parainfluenza & $12.9(39)$ & $26.1(6)$ & $11.1(29)$ & $21.1(4)$ & 13.7 \\
Human bocavirus & $7.9(24)$ & $17.4(4)$ & $4.5(12)$ & $5.3(1)$ & 8.3 \\
HMPV & $5.2(16)$ & $4.3(1)$ & $5.3(14)$ & $5.3(1)$ & 7.1 \\
Adenovirus & $4.9(15)$ & $4.3(1)$ & $3(8)$ & $5.3(1)$ & 12.5 \\
Coronavirus & $3.9(12)$ & $13(3)$ & $3(8)$ & $15.8(3)$ & 37.5 \\
\hline
\end{tabular}

$A$, number of viruses (multiple reproduction included); $B$, isolated viruses in patients who died (multiple reproductions included); $C$, number of viruses (multiple reproduction excluded); $D$, isolated viruses in patients who died (multiple reproduction excluded); $E$, rate of mortality for a single virus (D/C); Number of patients ( $n$ )

Table 4: Relationship between indication of PICU Admission, organ failure, and virus type (\%)

\begin{tabular}{|c|c|c|c|c|c|c|c|c|c|c|}
\hline $\begin{array}{l}\text { Indications of } \\
\text { hospitalization and } \\
\text { organ failures }\end{array}$ & ओे & 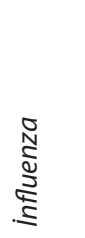 & 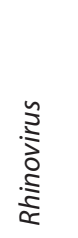 & 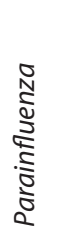 & 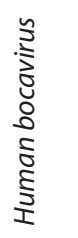 & 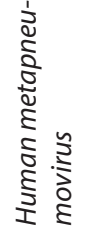 & 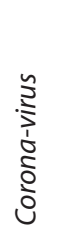 & 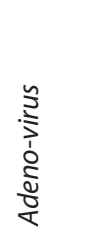 & 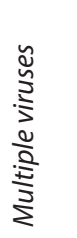 & $p^{*}$ \\
\hline Circulatory dysfunction & 9.4 & 11.1 & 2.6 & 13.8 & 8.3 & 7.1 & 12.5 & 37.5 & 12.2 & 0.43 \\
\hline Pulmonary dysfunction & 83 & 37.8 & 76.9 & 65.5 & 50 & 92.9 & 75 & 37.5 & 82.9 & 0.72 \\
\hline Neurologic dysfunction & 4.7 & 26.7 & 7.7 & 6.9 & 8.3 & 0 & 0 & 0 & 0 & 0.058 \\
\hline Multiorgan failure & 2.8 & 24.4 & 10.3 & 13.8 & 33.3 & 0 & 12.5 & 25 & 7.3 & 0.48 \\
\hline Respiratory failure & 94.3 & 75.6 & 92.3 & 96.6 & 83.3 & 100 & 100 & 87.5 & 95.1 & 0.74 \\
\hline Cardiovascular failure & 15.2 & 33.3 & 12.8 & 27.6 & 41.7 & 21.4 & 25 & 62.5 & 19.5 & 0.34 \\
\hline Neurologic failure & 5.7 & 37.8 & 17.9 & 24.1 & 25 & 0 & 12.5 & 0 & 9.3 & 0.37 \\
\hline Hepatic failure & 3.8 & 20 & 10.3 & 10.3 & 16.7 & 0 & 37.5 & 25 & 7.3 & 0.28 \\
\hline Renal failure & 2.8 & 24.4 & 7.7 & 13.8 & 25 & 0 & 25 & 25 & 7.5 & 0.41 \\
\hline Hematologic failure & 8.7 & 31.1 & 13.9 & 10.3 & 16.7 & 7.7 & 37.5 & 50 & 12.5 & 0.18 \\
\hline
\end{tabular}

${ }^{*} p$ is significant when it is $<0.05$

significant difference was found between the patients who died and discharged in terms of chest radiograph findings.

Out of all, $53.3 \%$ patients had underlying disease [neurologic in $17.8 \%$, respiratory in $16.5 \%$, cardiovascular in $12.5 \%$, immunological in $6.2 \%$, hematological-oncological in $5.9 \%$, renal in $2.3 \%$, and others (metabolic disease, chromosomal anomalies) 9.5\%]. Sixty percent of patients who died had underlying disease. This rate was $52 \%$ in discharged patients ( $p>0.05$ ).

The total number of viruses detected in nasal swabs of patients hospitalized in PICU, number of viruses when multiple reproductions were included and excluded in the patients who died, mortality rates when the viruses were evaluated in themselves are shown in Table 3. Multiple viruses were detected in 13\% of all patients. Multiple viruses isolated was in $17.3 \%$ of the patients who died and in $13.2 \%$ of the discharged patients $(p>0.05)$. For patients detected with a single-virus infection, there was statistically no difference between the species of the virus, between patients who survived, and patients who died $(p=0.195)$. When the viruses were evaluated among themselves and patients with multiple viruses were excluded, $37 \%$ of patients with coronavirus were found to have died (Table 3).
Median age of patients with influenza was 41 (11-75) months and median age of patients with the viruses other than influenza was 10 (3.5-28) months ( $p<0.001)$. The median PRISM score was 22 (8-27) and median PELOD score was 11 (3-21) in patients with influenza. The median PRISM score was 9 (3-17) and median PELOD score was 10 (1-15) in patients with the viruses other than influenza $(p<0.005)$. The relationships between the indication of PICU admission, organ failures at the time of admission or revealed at follow-up, and species of viruses isolated are shown in Table 4. Among all, $60.2 \%$ of patients received antiviral therapy, $94.3 \%$ antibiotic therapy, $15.8 \%$ antifungal therapy. $47.4 \%$ of patients who died, and $61.6 \%$ of the patients discharged received antiviral therapy $(p=0.22)$. The median duration of stay on MV was $4(2-5)$ days, median duration of stay in PICU was 7 (4-15), and median duration of hospital was 15 (10-27) days in patients who received antiviral therapy. The median duration of stay on MV was 3 (2-5) days, median duration of stay in PICU was 7 (3-13), and median duration of hospital was 15 (8-28) days in the patients who did not receive antiviral therapy $(p>0.05)$. It was found that virus species did not affect mortality between patients who received and did not receive antiviral therapy (Table 5). 
Table 5: Effect of antiviral treatment on mortality according to virus species

\begin{tabular}{|c|c|c|c|c|c|}
\hline \multirow[b]{3}{*}{ Virus species } & \multicolumn{4}{|c|}{ Antiviral treatment } & \multirow[b]{3}{*}{$p^{*}$} \\
\hline & \multicolumn{2}{|c|}{$\begin{array}{l}\text { Without } \\
\text { oseltamivir }\end{array}$} & \multicolumn{2}{|c|}{ Oseltamivir } & \\
\hline & $\begin{array}{l}\text { Patient } \\
\text { number }\end{array}$ & $\%$ & $\begin{array}{l}\text { Patient } \\
\text { number }\end{array}$ & $\%$ & \\
\hline Parainfluenza & 22 & 18,5 & 7 & 3,8 & \\
\hline RSV & 43 & 36,1 & 63 & 34,4 & \\
\hline İnfluenza & 6 & 5,0 & 39 & 21,3 & \\
\hline Rhinovirus & 18 & 15,1 & 21 & 11,5 & \\
\hline HMPV & 4 & 3,4 & 10 & 5,5 & 0.182 \\
\hline Human bocavirus & 5 & 4,2 & 7 & 3,8 & \\
\hline Coronavirus & 3 & 2,5 & 5 & 2,7 & \\
\hline Adenovirus & 2 & 1,7 & 6 & 3,3 & \\
\hline Multiple viruses & 16 & 13,4 & 25 & 13,7 & \\
\hline
\end{tabular}

${ }^{*} p$ is significant when it is $<0.05$

Bacterial infection was detected in the cultures of $16 \%$ of patients. There was bacterial infection in $43.5 \%$ of patients who died and in $14.5 \%$ of patients who were discharged $(p=0.001)$. Secondary bacterial infection was detected in $37.5 \%$ of patients with coronavirus, $25 \%$ of patients with adenovirus, $20 \%$ of patients with influenza, $17,9 \%$ of patients with rhinovirus, $17.2 \%$ of patients with parainfluenza, $14.3 \%$ of patients with RSV, and $7.1 \%$ of patients with HMPV. There was statistically no difference between the viruses in terms of development of secondary bacterial infection ( $p=0.5)$.

Of all, $92.3 \%$ of patients required respiratory support treatments. Renal replacement therapy was performed in $6.6 \%$, plasma exchange in $5.2 \%$, and ECMO in $1.9 \%$ of patients.

\section{Discussion}

Viral respiratory tract infections are the most common infections worldwide. They are the most important cause of mortality in all age groups, particularly in children. ${ }^{7}$ This retrospective observational study was conducted in order to analyze the course of seasonal viral infections of respiratory tract in patients hospitalized in PICUs of 16 centers representing the whole country. There are a bunch of studies in literature investigating the relationship between viruses and morbidity, comparison of single-multiple viruses or relationship between diseases and viruses. ${ }^{8-18}$ Current study is multi-directional and has comprehensively analyzed all these issues in a very large population requiring PICU.

Viral respiratory tract infections constitute significant proportion of patients admitted to PICUs in winter, and these patients require advanced intensive care support with high mortality and morbidity rates. In line with this, our study group shows a very high mortality rate as $7.6 \%$, which supports the justification of this multicenter survey. Although respiratory tract viruses commonly cause lower respiratory tract infections, presentation with extrapulmonary clinical manifestations are also likely in children under one year of age. ${ }^{8,19}$ Similarly, the most common cause of hospitalization was respiratory symptoms in our study. Fever, neurological symptoms, circulatory disorders, and shock were more common indications for hospitalization in patients under one year compared to older children (Table 2). In patients over one year of age presenting with respiratory symptoms, hypoxia as well as a need for MV were more common. We attributed this situation to RSV, which was more frequently observed in this age group. In the literature, RSV is more prevalent in infancy for PICU admission though influenza and bocavirus that was more common in our patients less than one year of age. ${ }^{1,9,10}$

We statistically evaluated all initial symptoms (clinical, laboratory, and radiological) and virus species through four parameters (duration of stay on mechanical ventilation (MV), duration of stay in PICU, duration of hospitalization, and mortality). Accordingly, we assessed relationship among presenting symptoms, virus species, and severity of disease. It was observed that presenting symptoms that have an effect on mortality were neurologic symptoms, hypotension, tachycardia, and hypoxia. It was also found that liver and renal function test abnormalities, higher lactate values were related with death. Eighty-seven percent of mortalities are presented with acidosis (Table 1). The critical pH value related with mortality and critical $\mathrm{PCO}_{2}$ was $\leq 7.10$ and $\geq 60 \mathrm{~mm}$ $\mathrm{Hg}$, respectively. In regression analysis, acidosis alone was found to increase mortality by 2.5 folds. In the light of these findings, it can be predicted that patients with neurological symptoms, tachycardia, hypotension, low levels of pulse $\mathrm{sO}_{2}$, acidosis, and impaired liver or renal function at the time of admission will have a higher morbidity and mortality.

Kumar et al. showed that organ failure in patients hospitalized in ICU with H1N1 infection increased mortality. ${ }^{11}$ Also, Kendirli et al. demonstrated the correlation between organ failures and mortality in the patients who presented with H1N1 infection. ${ }^{12}$ Similarly, in our study, mortality rates were higher and in regression analysis, we demonstrated that initial presentation with MODS increased mortality by 20 -folds.

In a study, it was shown that RSV was the most common agent in patients who needed intensive care. ${ }^{20}$ This is definitely compatible with our findings.

Spaeder and Fackler reported that virus species did not affect durations of stay in PICU and hospital, as well as development of MODS and mortality. ${ }^{21}$ In our study, we also investigated virus species organ failure relationship and emerging indications for PICU admission. We demonstrated that there was no correlation between virus species and diagnosis of admission to PICU or type of organ failure developed (Table 4). However, $63 \%$ of the patients who died in 2017 winter season had RSV, parainfluenza or influenza. Secondary bacterial agent was observed in about half of the patients who died. It is not easy to blame viral agents to be the leading causes of mortality because of the frequent accompaniment of secondary bacterial agents. Similar to the literature, we found that secondary bacterial infections negatively affected mortality. $15,22,23$

In the present study, multiple viruses were detected in $13 \%$ of the patients. Although there are also contrary opinions, ${ }^{24-26}$ detection of multiple viruses does not affect mortality and duration of stay in PICU. ${ }^{22,27,28}$ Similarly, we showed that multiple viruses did not affect mortality.

When multiple virus isolated patients were excluded, coronavirus revealed to be the most lethal virus as three out of eight patients with coronavirus died (Table 3). Coronavirus is known as the primary agent of upper respiratory tract infection and common cold. ${ }^{29}$ Coronavirus had been defined as the causal agent of SARS (Severe Acute Respiratory Syndrome), which more severely progresses in adults, while the disease lasts shorter and shows milder progression in children. ${ }^{30}$ Unlike the literature, coronavirus presented severe symptoms with organ failures in 
our group of patients (Table 4). Lower respiratory tract infections caused by coronavirus types out of SARS are rare and some studies found the incidence of pneumonia and bronchitis as $<5 \% .{ }^{31-36}$ Therefore, in our study, the incidence of coronavirus was low that is consistent with the literature, but unlike that coronavirus caused lower respiratory tract infections and emerged as the most lethal viral agent (Table 3). However, $36 \%$ of the patients with coronavirus had secondary bacterial infections; so, coronavirus is not solely responsible for mortality.

Although secondary infections were found in only $16 \%$ of all patients, we found that $94 \%$ of the patients who presented with viral infections received antibiotics.

Sixty-two percent of the patients received antiviral treatment (oseltamivir) because antiviral therapy was started before nasal swab results in patients with severe infection findings. We found that antiviral therapy did not affect mortality (Table 5) including the influenza subgroup. Though, there are studies in literature showing that oseltamivir initiated in the early period was effective. ${ }^{37-39}$ However, weakness of our study is that the data we gathered is not capable of differentiating the initiation timing for antiviral therapy. Further studies are needed for this issue. Influenza is already known as the only agent that benefits from oseltamivir. When we separately evaluated the influenza subgroup, we found the median patient age as 41 months and higher PRISM and PELOD scores compared with rest of the viral agents. Influenza was more common in older children and progressed more severely. Therefore, oseltamivir can be preferred in children especially over one year of age and who presented with more severe symptoms because they are more likely to have influenza.

Consistent with the literature, comorbidities were common in the present study. ${ }^{9,12-14,20}$ Although $60 \%$ of the patients who died had an underlying disease, a statistical correlation is lacking as described in the literature. ${ }^{9,12}$

In our study, it was found that mechanical respiratory support was administered to the majority of the patients and renal replacement therapy was applied in the group, which had organ failure and progression. As expected, we found that PRISM and PELOD scores were higher in patients who died.

\section{CONCLUSION}

We found that tachycardia, hypotension, hypoxia, acidosis, impaired liver or renal tests, and MODS at the time of admission are the factors associated with mortality and predictors of a severely progressing disease. It was found that acidosis increased mortality by 2.5 -folds and MODS by 20 -folds. Respiratory symptoms were common and besides respiratory symptoms, incidence of circulatory disorders and shock findings were also high in patients less than one year of age. Fever, tachycardia, neurologic symptoms, the incidence of anemia, leukocytosis, thrombocytopenia, impaired renal tests, and electrolyte imbalance were high in patients less than one year of age. Consequently, acidosis and MODS at the time of admission or a patient less than one year of age with symptoms mentioned above should alert clinicians for a possible poor prognosis. Although we could not show the relationship of virus type with severity and mortality, RSV, parainfluenza, and influenza were the commonly isolated viruses in the patients who died. Coronavirus was found as the most lethal virus. Although coronavirus is known as the primary agent of upper respiratory tract infection and common cold, this result of our study can be attributed to the incidence of secondary bacterial infections being high in the patients with coronavirus detected. With this context, further studies are needed to investigate the relationship between coronavirus and mortality.

In our study, we could not demonstrate effects of oseltamivir on mortality, duration of hospitalization, and stay in the PICU including influenza subgroup but there are studies reporting that oseltamivir initiated within first 48 hours is beneficial. Therefore, oseltamivir can be preferred in children who present with more severe symptoms because they are more likely to have influenza.

\section{ACKNOWLedgments}

Authors would like to thank Dr. Ersoy Civelek for statistical analysis and all participants for their contributions.

\section{References}

1. Pavia AT. Viral infections of the lower respiratory tract: old viruses, new viruses, and the role of diagnosis. Clin Infect Dis. 2011; 52 Suppl 4: 284-289. doi: 10.1093/cid/cir043

2. Wong-Chew RM, Garcia-Leon ML, Noyola DE, Perez Gonzalez LF, Gaitan Meza J, Vilasenor Sierra A, et al. Respiratory viruses detected in Mexican children younger than 5 years old with community-acquired pneumonia: a national multicenter. Int J Infect Dis. 2017; 62:32-38. doi: 10.1016/j.ijid.2017.06.020

3. Jain S, Williams DJ, Arnold SR, Ampofo K, Bramley AM, Reed C, et al. Community acquired pneumonia requiring hospitalization among U.S. children. N Engl J Med. 2015; 372: 835-845. doi: 10.1056/ NEJMoa1405870

4. Akçalı S, Yılmaz N, Güler O, Sanildag T, Anıl M. Frequency of respiratory viruses in children with lower respiratory tract infection. Turkish Arch Pediatr.. 2013; 48: 215-220.

5. Centers for Disease Control and Prevention. Prevention and Control of influenza: recommendations of the Immunization Practices Advisory Committee (ACIP). Morb Mortal Wkly Rep. 1995; 44: 1-22.

6. Goldstein B, Giroir B, Randolph A. International pediatric sepsis consensus conference: definitions for sepsis and organ dysfunction in pediatrics. Pediatr Crit Care Med. 2005; 6:2-8. doi: 10.1097/01. PCC.0000149131.72248.E6

7. Bryce J, Boschi-Pinto C, Shibuya K, Black RE. WHO estimates of the causes of death in children. Lancet. 2005; 365: 1147-1152. doi: 10.1016/ S0140-6736(05)71877-8

8. Eisenhut M, Extrapulmonary manifestations of severe respiratory syncytial virus infection-a systematic review. Crit Care. 2006;10: R107. doi: $10.1186 /$ cc4984

9. Njoku DB, Kliegman RM. Atypical extrapulmonary presentations of severe respiratory syncytial virus infection requiring intensive care. Clin Pediatr (Phila). 1993; 32: 455-460. doi: 10.1177/000992289303200802

10. Moesker FM, van Kampen JJ, van der Eijk AA, van Rossum AMJ, de Hoog M, Schutten M, et al. Human bocavirus infection as a cause of severe acute respiratory tract infection in children. Clin Microbiol Infect. 2015; 21: 964.1-8. doi: 10.1016/j.cmi.2015.06.014

11. Kumar A, Zarychanski R, Pinto R, Cook DJ, Marshall J, Lacroix J, et al. Critically ill patients with 2009 influenza A(H1N1) infection in Canada. JAMA. 2009; 302:1872-1879. doi: 10.1001/jama.2009

12. Kendirli T, Demirkol D, Yildizdas D, Anıl AB, Acsılıoglu N, Karapınar B, et al. Critically ill children with pandemic influenza (H1N1) in pediatric intensive care units in Turkey. Pediatr Crit Care Med. 2012; 13: e11-e17. doi: 10.1097/PCC.0b013e31820aba37

13. Lockman JL, Fischer WA, Perl TM, Valsamakis A, Nichols DG. The critically ill child with novel H1N1 influenza A: a case series. Pediatric Crit Care Med. 2010; 11:173-178. doi: 10.1097/PCC.0b013e3181ccedae

14. Streng A, Prifert C, Weissbrich B, Liese JG. Continued high incidence of children with severe influenza $A(\mathrm{H} 1 \mathrm{~N} 1)$ pdm09 admitted to paediatric intensive care units in Germany during the first three post-pandemic influenza seasons, 2010/11-2012/13. BMC Infect Dis. 2015; 15:573. doi: $10.1186 / s 12879-015-1293-1$ 
15. Sachedina N, Donaldson LJ. Paediatric mortality related to pandemic influenza A H1N1 infection in England: an observational populationbased study. Lancet. 2010; 376: 1846-1852. doi: 10.1016/S01406736(10)61195-6

16. Van de Pol AC, Wolfs TF, Jansen NJ, Kimpen JLL, van Loon AM, Rossen JWA. Human bocavirus and $\mathrm{KI} / \mathrm{WU}$ polyomaviruses in pediatric intensive care patients. Emerg Infect Dis. 2009; 15: 454-457. doi: 10.3201/eid1503.081203

17. Mullins JA, Erdman DD, Weinberg GA, Edwaeds K, Hall CB, Walker FJ, et al. Human metapneumovirus infection among children hospitalized with acute respiratory illness. Emerg Infect Dis. 2004; 10: 700-705. doi: 10.3201/eid1004.030555

18. Kim KY, Han SY, Kim HS, Cheong HM, Kim SS, Kim DS. Human coronavirus in the 2014 winter season as a cause of lower respiratory tract infection. Yonsei Med J. 2017; 58:174-179. doi: doi: 10.3349/ ymj.2017.58.1.174

19. Tregoning JS, Schwarze J. Respiratory viral infections in infants: causes, clinical symptoms, virology, and immunology. Clin Microbiol Rev. 2010; 23: 74-98. doi: 10.1128/CMR.00032-09

20. Hon KL, Leung E, Tang J, Chow CM, Leung TF, Cheung KL, et al. Premorbid factors and outcomes associated with respiratory virus infections in a pediatric intensive care unit. Pediatr Pulmonol. 2008; 43: 275-280. doi: 10.1002/ppul.20768

21. Spaeder MC, Fackler JC. Hospital-acquired viral infection increases mortality in children with severe viral respiratory infection. Pediatr Crit Care Med. 2011; 12: 317-321. doi: 10.1097/PCC.0b013e3182230f6e

22. Ghani AS, Morrow BM, Hardie DR, Argent AC. An investigation into the prevalence and outcome of patients admitted to a pediatric intensive care unit with viral respiratory tract infections in Cape Town, South Africa. Pediatr Crit Care Med. 2012; 13(5):e275-e281. doi: 10.1097/ PCC.0b013e3182417848

23. Klein EY, Monteforte B, Gupta A, Jiang W, May L, Hsieh YH, et al. The frequency of influenza and bacterial coinfection: a systematic review and meta-analysis. Influenza Other Respir Viruses. 2016; 10: 394-403. doi: 10.1111/irv.12398

24. Richard N, Komurian-Pradel F, Javouhey E, Perret M, Rajoharison $A$, Bagnaud $A$, et al. The impact of dual viral infection in infants admitted to a pediatric intensive care unit associated with severe bronchiolitis. Pediatr Infect Dis J. 2008; 27:213-217. doi: 10.1097/ INF.0b013e31815b4935

25. Rehder KJ, Wilson EA, Zimmerman KO, Cunningham CK, Turner $\mathrm{DA}$, et al. Detection of multiple respiratory viruses associated with mortality and severity of illness in children. Pediatr Crit Care Med. 2015; 16: 201-206. doi: 10.1097/PCC.0000000000000492

26. Chauhan JC, Slamon NB. The impact of multiple viral respiratory infections on outcomes for critically ill children. Pediatr Crit Care Med. 2017;18: e333-e338. doi: 10.1097/PCC.0000000000001232
27. Fitch PM, Henderson P, Schwarze J. Respiratory and gastrointestinal epithelial modulation of the immune response during viral infection. Innate Immun. 2012; 18:179-189. doi: 10.1177/1753425910391826

28. Van de Pol AC, Wolfs TF, Jansen NJ, van Loon AM, Rossen JW Diagnostic value of real time polymerase chain reaction to detect viruses in young children admitted to the paediatric intensive care unit with lower respiratory tract infection. Crit Care. 2006;10: R61. doi: $10.1186 /$ cc4895

29. van Elden LJ, van Loon AM, van Alphen F, Hendriksen KA, Hoepelman $\mathrm{Al}$, van Kraai, et al. Frequent detection of human coronaviruses in clinical specimens from patients with respiratory tract infection by use of a novel real-time reverse- transcriptase polymerase chain reaction. J Infect Dis. 2004; 189:652-657. doi: 10.1086/381207

30. Dowell SF, Ho MS. Seasonality of infectious diseases and severe acute respiratory syndrome - what we don't know can hurt us. Lancet Infect Dis. 2004; 4:704-708. doi: 10.1016/S1473-3099(04)01177-6

31. Leung CW, Chiu WK. Clinical picture, diagnosis, treatment and outcome of severe acute respiratory syndrome (SARS) in children. Paediatr Respir Rev. 2004; 5: 275-288. doi: 10.1016/j.prrv.2004.07.010

32. Esposito S, Bosis S, Niesters HG, Tremolati E, Begliatti E, Rognoni A, et al. Impact of human coronavirus infections in otherwise healthy children who attended an emergency department. J Med Virol. 2006; 78:1609-1615. doi: 10.1002/jmv.20745

33. Kuypers J, Martin ET, Heugel J, Wright N, Morrow R, Englund JA. Clinical disease in children associated with newly described coronavirus-subtypes. Pediatrics. 2007; 119: 70-76. doi: 10.1542/ peds.2006-1406

34. Wu PS, Chang LY, Berkhout B, van der Hoek L, Lu CY, Kao CL, et al. Clinical manifestation of human coronavirus NL63 infection in children in Taiwan. Eur J Pediatr. 2008; 167: 75-80. doi: 10.1007/ s00431-007-0429-8

35. Smuts H, Workman L, Zar HJ. Role of human metapneumovirus, human coronavirus NL63 and human bocavirus in infants and young children with acute wheezing. J Med Virol. 2008; 80: 906-912. doi: 10.1002/jmv.21135

36. Vabret A, Dina J, Gouarin S, Petitjean J, Corbet S, Freymuth F. Detection of the new human coronavirus HKU1: a report of 6 cases. Clin Infect Dis. 2006; 42:634-639. doi: 10.1086/500136

37. Lee N, Choi KW, Chan PK, Hui DS, Lui GC, Wong BC, et al. Outcomes of adults hospitalized with influenza. Thorax. 2010; 65: 510-515. doi: $10.1136 /$ thx.2009.130799

38. Kumar A. Early versus late oseltamivir treatment in severely ill patients with 2009 pandemic influenza A (H1N1): speed is life. J Antimicrob Chemother. 2011; 66: 959-963. doi: 10.1093/jac/dkr090

39. Sugaya N, Shinjoh M, Mitamura K, Takahashi T. Very low pandemic influenza A (H1N1) 2009 mortality associated with early neuraminidase inhibitor treatment in Japan: analysis of 1000 hospitalized children.J Infect. 2011; 63: 288-294. doi: 10.1016/j.jinf.2011.06.008 